\title{
Tradução/traduções: uma perspectiva no estudo das divergências entre PE e PB
}

Vanessa Castagna ${ }^{1}$

\begin{abstract}
The present study aims to explore the diatopic differences internal to the Portuguese language, particularly in its European and Brazilian varieties. More specifically, the analysis intends to point out the peculiarities of PB in relation to PE that emerge in the literary translation of narrative texts, by comparing peculiar parallel texts, that is, versions of the same literary works, published in Portugal and Brazil in the same period. As a specific case study, the comparative analysis of the Portuguese and Brazilian translations of short fictional texts by the Italian writer Italo Calvino, whose style is marked by clarity and precision, is presented. The analysis explores relevant elements at lexical and grammatical level, and of register variation, based on data of contrastive linguistics and the typical approach of descriptive translation studies.
\end{abstract}

Keywords: translation; translated literature; European Portuguese and Brazilian Portuguese.

Resumo: O presente estudo visa explorar as diferenças diatópicas internas à língua Portuguesa, em particular nas suas variedades europeia e brasileira. Mais em particular, a análise pretende apontar para as especificidades do PB face ao PE que emergem na tradução literária de textos narrativos, através da comparação de peculiares textos paralelos, ou seja, de versões das mesmas obras literárias publicadas em Portugal e no Brasil na mesma época. Como caso de estudo concreto, é apresentada a análise comparativa das traduções portuguesas e brasileiras de breves textos ficcionais da autoria do escritor italiano Italo Calvino, cujo estilo é marcado pela clareza e pela precisão. A análise explicita elementos relevantes no plano lexical, gramatical e da variação de registo, fundamentando-se em dados de linguística contrastiva e na abordagem típica dos estudos descritivos de tradução.

Palavras-chave: tradução, literatura traduzida; PE e PB.

Introdução

A comparação de textos paralelos é uma prática especialmente reveladora das diferenças que intercorrem entre dois ou mais sistemas linguísticos e culturais. Ao mesmo tempo, muitas vezes é difícil conseguir uma observação eficaz, devido à comparabilidade apenas parcial dos textos disponíveis. Se em tipologias textuais muito normativas essa comparação é relativamente fácil, muito mais complicado se revela encontrar textos que pertencem a tipologias pouco vinculadoras e que sejam altamente comparáveis ${ }^{2}$. No caso

1 Universidade de Veneza.

2 O quadro a que fazemos implicitamente referência é resumido na tabela que incluímos como Apêndice, proposta por Federica Scarpa, que por sua vez adapta a proposta do linguista italiano Francesco Sabatini ao âmbito da tradução de textos de especialidade. 
dos textos literários, as traduções de um mesmo texto-fonte podem, no entanto, suprir essa dificuldade e fornecer, pelo contrário, material autêntico, manifestação paralela de dois sistemas linguísticos e culturais.

Dessas considerações surge a ideia de constituir um estudo de caso a partir de um corpus definido, necessariamente limitado e destinado a apresentar-se como amostra de fenômenos linguísticos e tradutivos passíveis de futura confirmação. Para a definição do corpus a examinar, com vista a uma efetiva representatividade do caso de estudo e uma real comparabilidade dos textos, foram consideradas prioritárias algumas características: prestígio do autor e da obra; contemporaneidade dos textos originais (prototexto) e das traduções (metatextos); elevada afinidade linguística entre os idiomas envolvidos no processo tradutório, que possibilitasse, em princípio, uma consistente conservação da estrutura frásica e do estilo dos prototextos nos respetivos metatextos.

O quadro teórico a que fazemos referência é o dos estudos descritivos de tradução inaugurados por Gideon Toury. De acordo com este enquadramento, que surge na área mais específica da tradução literária, de fato admite-se que uma tradução publicada num dado país e num dado momento reflete um sistema de normas implícito sobre como essa tradução deverá ser feita para ser aceita como uma boa tradução.

$\mathrm{Na}$ tensão que caracteriza o trabalho do tradutor entre a adequação - que privilegia a adesão às normas do sistema cultural de partida - e a aceitabilidade - com a adesão às normas do sistema cultural de chegada (cfr. Toury 1995: 57) - é elaborado o metatexto, que tenderá a aproximar-se das normas e práticas (extralinguísticas, mas também linguísticas) da cultura recipiente. A observação desse processo, portanto, pode revelar aspetos significativos precisamente do sistema de normas implícitas que regem a prática tradutória numa determinada época e num determinado espaço cultural.

Em particular, interessa aqui explorar o modelo linguístico implícito que subjaz à tradução literária no Brasil, sobretudo tendo em conta que os testemas do prototexto tendem a ser transformados em repertoremas na língua e cultura de chegada (Toury 1995: 268). Isso significa que as marcas características do texto fonte tendem a ser convertidas em marcas de um repertório (sujeito a relações sistémicas) e não simplesmente do metatexto. Nessa perspetiva, a literatura traduzida é sem dúvida uma área de estudo pertinente para os fenômenos de variação linguística.

A esse quadro teórico se cruzam, para uma observação mais eficaz, elementos de linguística contrastiva, não só no sentido de comparar as duas variedades internas do português em análise (PE e PB), mas também a fim de selecionar itens significativos na língua portuguesa em contraposição à língua-fonte, uma vez que nas especificidades do português, isto é nos elementos que o diferenciam de outros idiomas, é onde se podem observar alguns fenómenos peculiarmente caracterizadores.

\section{Definição do corpus e caso de estudo}

Com base em todas as premissas ilustradas e atentando em critérios determinados pela prioridade atribuída às características de prestígio da obra, contemporaneidade de prototextos e metatextos e afinidade entre língua-fonte e português, para constituição do caso de estudo selecionaram-se algumas traduções portuguesas e brasileiras dos mesmos textos de um autor italiano contemporâneo absolutamente consagrado, ou seja, Italo Calvino.

Italo Calvino é considerado um dos maiores escritores do século XX e ocupa uma posição única no panorama italiano devido à variedade da sua obra, à sua linha de evolução 
literária e à sua voz particularmente ativa nos debates literários do século XX. Além disso, trata-se de um dos autores italianos mais difusos e conhecidos no mundo, com livros publicados em 64 países e traduzidos em 45 línguas, incluindo o Português.

No que diz respeito a Portugal e ao Brasil, as primeiras obras do autor chegaram no início dos anos 60 e nos anos 80 respectivamente, estando atualmente todas as obras principais (e até várias obras consideradas "menores”) traduzidas nos dois países, em edições distintas e na maior parte dos casos já com várias reedições.

O corpus é constituído pela primeira "cosmicómica", ou seja La distanza della Luna (A distância da Lua), o primeiro conto de Gli amori difficili (Os amores difíceis), isto é L'avventura di un soldato (A aventura de um soldado), e pelas "cidades" (55 microtextos ao todo) evocadas em Le città invisibili ${ }^{3}$ (As cidades invisíveis) ${ }^{4}$. As datas de publicação destas obras e das respetivas traduções são as seguintes:

- Le cosmicomiche: 1965; Todas as cosmicómicas na tradução portuguesa de José Colaço Barreiros, com revisão de Miguel Martins Rodrigues (1993), e Todas as cosmicômicas na tradução brasileira de Ivo Barroso e Roberta Barni (2007)

- Gli amori difficili: 1970; Os amores difíceis na tradução portuguesa de José Colaço Barreiros, com revisão de Miguel Martins Rodrigues $(2011)^{6}$, e na tradução brasileira de Raquel Ramalhete (1992);

- Le città invisibili: 1972; As cidades invisíveis na tradução portuguesa de José Colaço Barreiros (1993) e na tradução brasileira de Diogo Mainardi (1990).

Se a tradução em Portugal foi a cargo do mesmo tradutor, no Brasil a tradução das obras em análise envolveu tradutores diferentes, o que torna mais dinâmico o objeto de estudo. O período abrangido pelas traduções é bastante homogêneo, em especial os metatextos brasileiros datam todos eles da década de 90 , mas têm uma persistência no mercado livreiro brasileiro até aos dias de hoje, como se comprova pelas contínuas reedições e reimpressões.

O estudo será realizado através da exploração dos metatextos em PE e PB como textos paralelos, capazes de refletir os respectivos sistemas implícitos de normas, no intuito, em particular, de medir o nível de incorporação dos fenômenos de variação linguística na literatura traduzida no Brasil. Em especial, como se explicitou acima, pretende-se investigar como é o português das traduções brasileiras e, mais concretamente, em que medida as traduções refletem as crescentes divergências entre PE e PB, que cada vez mais se patenteiam em textos produzidos autonomamente nas duas variedades de português.

Como referimos, o facto de se tratar de traduções a partir de uma língua romance, considerada afim ao português, permite limitar o risco de ter versões demasiado divergentes entre si, em virtude da ampla transferibilidade da organização discursiva e dos recursos estilísticos de uma língua para outra.

3 Esta obra de Calvino é um romance construído com a técnica do jogo combinatório. Do corpus excluímos os diálogos entre Marco Polo (o narrador) e Kublai Kan, que constroem a estrutura em que os blocos de "cidades" se inserem.

4 Por motivos de brevidade, nas referências aos textos utilizaremos as abreviaturas, respetivamente, de $A L, A S$ e $C I$.

5 Na edição brasileira indicada conflui a anterior tradução de As cosmicômicas, de Ivo Barroso, que remonta a 1992 e que já inclui o conto escolhido para constituição do corpus em análise.

6 A mesma obra já tinha sido traduzida em Portugal por Manuel Duarte (Lisboa, Arcádia, 1968), mas por necessidade de comparabilidade entre metatextos foi descartada para o presente estudo de caso. 


\section{Análise comparativa}

A comparação dos metatextos descritos, portugueses e brasileiros, a uma primeira vista fornece uma imagem de grande proximidade entre o PE e o PB, sendo que em particular as traduções brasileiras mantêm um nível de formalidade muito elevado, com um registo marcadamente cuidado. O que caracteriza o corpus em análise no seu conjunto é que na maior parte das passagens examinadas os elementos de divergência entre PE e PB são quase impercetíveis.

Como era de esperar, detectam-se divergências lexicais, que podemos resumir na seguinte lista de palavras ${ }^{7}$, que apenas testemunham diferenças lexicais conhecidas, independentes da mera escolha do tradutor. Pela tabela abaixo, organizada por ordem alfabética da palavra em italiano e substantivos apresentados no singular (exceto no caso de nomes coletivos), pode-se observar que o número de divergências no plano lexical impostas em si pelas diferentes variedades linguísticas é limitado:

\begin{tabular}{|l|l|l|}
\hline Italiano & Tradução portuguesa & Tradução brasileira \\
\hline bisnonno & bisavô & bisnono \\
\hline boccia & bola & bocha \\
\hline calamita & imã & ímã \\
\hline cane & cão & cachorro \\
\hline cartolina & postal & cartão-postal \\
\hline cogliere di sorpresa & apanhar de surpresa & pegar de surpresa \\
\hline erba & erva & grama \\
\hline erbivendola & ervanária & quitanda \\
& vendedeira de hortaliças & quitandeira \\
\hline frigorifero & frigorífico & geladeira \\
\hline fumatore & fumador & fumante \\
\hline idraulico & canalizador & encanador \\
\hline lotta dei galli & luta de galos & briga de galos \\
\hline maneggio & oficina dos ferradores & haras \\
\hline pistacchio & pistáquio & pistache \\
\hline prato & relva & $\begin{array}{l}\text { grama } \\
\text { gramado }\end{array}$ \\
\hline purè & puré & mingau \\
\hline sedici & dezasseis & dezesseis \\
\hline stanza & sala & cômodo \\
\hline spaghetti & spaghetti & espaguete \\
\hline
\end{tabular}

7 Omitimos as diferenças de tipo ortográfico/fonético que não impliquem diferença de sílaba tónica e que podem ter sido minimizadas na sequência da entrada em vigor do Acordo Ortográfico de 1990, que, no entanto, como é sabido não pôde apagar muitas dessas diferenças (por exemplo, em palavras como contacto/ contato). 


\begin{tabular}{|l|l|l|}
\hline termite & térmita & cupim \\
\hline treno & comboio & trem \\
\hline
\end{tabular}

Nota: 1 Contudo na tradução de Diogo Mainardi surge o termo "fumador" (As cidades e os símbolos. 4).

Tabela 1. Diferenças de léxico determinadas pelo uso em PE e PB.

À lista acima, poder-se-ia acrescentar a ocorrência de aterrissar (tendo como equivalente em PE aterrar), que, porém, no caso concreto traduz o italiano toccare terra e que na tradução em PE surge de forma literal, ou seja tocar terra.

Nas traduções brasileiras, como se pode ver, surgem alguns brasileirismos que, na verdade, convivem no PB com sinônimos necessariamente usados no PE, como no caso de cupim, precisamente sinônimo de térmita, bem como o italianismo bisnono em vez de bisavô.

Por outro lado também é de assinalar que as traduções portuguesas mostram duas singularidades: o estrangeirismo spaghetti, em vez do mais comum esparguete; a forma pistáquio em vez do habitual pistácio. Contudo, em ambos os casos mesmo o empréstimo comummente usado no PE divergiria do PB. Quanto ao italiano boccia, o tradutor português opta por bola, que designa o objeto; porém no PE também se encontra dicionarizado o italianismo boccia para denominar o jogo ou a modalidade desportiva.

Vale a pena observar, ainda, que mingau é um brasileirismo e poderia ser interpretado como um elemento naturalizador dentro da tradução, que, porém, constitui caso isolado no metatexto em análise, já que Ivo Barroso não parece adotar uma estratégia naturalizadora na tradução analisada. Pelo contrário, por vezes a sua fidelidade à letra do conto de Italo Calvino leva-o a escolhas mais rebuscadas face à tradução portuguesa. Em particular, em $A$ distância da Lua, encontramos as seguintes correspondências que vale a pena destacar - a primeira com duas ocorrências ao longo do conto e a segunda com cinco (com oscilação entre singular e plural):

\begin{tabular}{|l|l|l|}
\hline Italiano & Tradução portuguesa & Tradução brasileira \\
\hline braccia argentee & braços prateados & braços argênteos \\
\hline plenilunio & lua cheia & plenilúnio \\
\hline
\end{tabular}

Sejam quais forem as razões dos tradutores ${ }^{8}$, o resultado é indubitavelmente que a tradução portuguesa apresenta nestes casos termos de uso comum, ao passo que a tradução brasileira incorpora termos mais cultos.

Já no plano gramatical, em geral os únicos elementos de divergência, são elementos perfeitamente previstos pela norma brasileira e sobejamente conhecidos ${ }^{9}$.

Sem considerar a ocorrência pontual de divergências de pormenor ${ }^{10}$, confirma-se, em particular, a preferência no PB pelo gerúndio em perífrases verbais que preveem o infinitivo no PE, como se observa numa das muitas ocorrências, por exemplo, em $A$ aventura do soldado (negrito e sublinhado nossos):

8 Há outra ocorrência do adjetivo argenteo no prototexto, referindo-se a água, que ambos os tradutores traduzem optando por prateado.

9 Numa perspetiva contrastiva focada no uso culto, cuidado e monitorizado do PB, entre outros estudos sobre o tema remetemos em especial para Mattos e Silva 2014.

10 Alguns dos raros fenómenos pontuais que surgem no corpus são, por exemplo, a partir do PB: o uso do particípio irregular pego não previsto em PE; a preposição até sem acréscimo de $a$ antes de um determinante (o que é obrigatório em PE); expressões como todo momento (“em qualquer momento" em PE). 
(IT) "Non s'è mossa, - pensava, - forse vuole", ma pensava anche: "Un attimo ancora e sarebbe troppo tardi. forse è lì che mi studia per fare una scenata".

(PE) "Nem se mexeu”, pensou, "talvez queira", mas pensou também: "Mais um instante e já seria tarde. Se calhar está para ali a estudar-me para me fazer alguma cena."

(PB) “Não se mexeu”, pensava, "talvez esteja querendo", mas pensava também: "Mais um instantinho e seria tarde demais. Talvez esteja me estudando para armar uma cena."

No breve trecho acima pode-se ainda observar que o recurso à perífrases verbal que expressa "ação durativa num momento rigoroso" (Cunha e Cintra 2002: 490) estende-se no $\mathrm{PB}$ a verbos com traços semânticos que os excluem de análogo uso no PE, como é o caso do verbo querer.

Outro elemento de divergência intrínseco no sistema linguístico é dado pela possibilidade e não obrigatoriedade, no $\mathrm{PB}$, de o determinante possessivo ser precedido de artigo definido, enquanto no PE o artigo definido é praticamente obrigatório. Essa divergência manifesta-se, portanto, em todas as traduções brasileiras que compõem o corpus, em casos como: "suas veias", "seu corpo", "sua abordagem", "sua mão" $(A S)$; "sua mãos", "meu primo", "nossas conchas", "meus pulos" $(D L)$; "minha memória”, "suas trilhas", "seu centro", "seu céu" $(C I)$, entre outros.

Confirma-se a expectativa de uma tendência divergente quanto à colocação pronominal, com a conhecida preferência no PB pela próclise em orações principais na ausência de "palavras atrativas" e ênclise em orações subordinadas em que no PE não seria recomendada. No entanto, nas traduções brasileiras registam-se numerosos casos de ênclise em posições que permitiriam colocação proclítica e de que damos apenas um exemplo:

Em Esmeraldina, cidade aquática, uma rede de canais e uma rede de ruas sobrepõe-se e entrecruza-se. Para ir de um lugar a outro, pode-se sempre escolher entre o percurso terrestre e o de barco: e, como em Esmeraldina a linha mais curta entre dois pontos não é uma reta mas um ziguezague que se ramifica em tortuosas variantes, os caminhos que se abrem para o transeunte não são dois mas muitos, e aumentam ainda mais para quem alterna trajetos de barco e transbordos em terra firme. (As cidades e as trocas. 5, PB, negrito e sublinhado nossos)

O chamado pronome solto, que não aparece no PE, surge nas traduções brasileiras mas de forma não sistemática, como se pode comprovar pelo exemplo abaixo, em que uma colocação enclítica tradicional antecede de poucas linhas um pronome anteposto ao particípio passado:

No compartimento, ao lado do infante Tomagra, veio sentar-se uma senhora alta e bem fornida. [...]

Mas, raciocinou Tomagra, ela, mesmo sendo uma senhora, não havia decerto mostrado ter repugnância por ele, pela aspereza da farda, senão teria se sentado mais longe. (A aventura do soldado, $P B$, negrito nosso)

Essa mesma tendência confirma-se ao longo das páginas dos restantes metatextos brasileiros analisados. 
No entanto, ao contrário das traduções portuguesas, nas traduções brasileiras de $A$ aventura de um soldado e de A distância da lua não se regista nenhum caso de mesóclise, fenômeno típico da língua Portuguesa e que não se encontra, portanto, no prototexto. Pelo contrário, na tradução de As cidades invisíveis de Diogo Mainardi registam-se três ocorrências dessa posição pronominal, ou seja um número parecido com o da versão portuguesa, que soma quatro ocorrências. Comparemos as diversas ocorrências (negrito e sublinhado nossos), que permitem também entrever os processos que levam à constituição de metatextos que, ao seguirem caminhos individualizados no processo tradutório, funcionam de fato como textos autônomos mas comparáveis:

(IT) men che meno ce lo si vedrebbe oggi (Le città e la memoria. 5)

(PE) igualmente não se veria hoje (As cidades e a memória. 5)

(PB) ver-se-ia ainda menos hoje em dia (As cidades e a memória. 5)

(IT) Si direbbe che gli idraulici abbiano compiuto il loro lavoro (Le città sottili. 3)

(PE) Dir-se-ia que os canalizadores acabaram o seu trabalho (As cidades subtis. 3)

(PB) Dir-se-ia que os encanadores concluíram o seu trabalho (As cidades delgadas. 3)

(IT) ti parlerò di dame che navigano (Le città e i segni. 5)

(PE) falar-te-ei de damas que navegam (As cidades e os sinais. 5)

(PB) falarei das mulheres que navegam (As cidades e os símbolos. 5)

(IT) i tuoi sguardi si impiglieranno raso terra (Le città e gli occhi. 2)

(PE) os nossos olhares prender-se-ão ao chão (As cidades e os olhos. 2)

(PB) cravará os olhos à altura do chão (As cidades e os olhos. 2)

(IT) basta percorrere un semicerchio e si avrà in vista la faccia nascosta di Moriana (Le città e gli occhi. 5)

(PE) basta percorrer um semicírculo e ter-se-á à vista a face oculta de Moriana ( $A s$ cidades e os olhos. 5) 
(PB) basta percorrer um círculo e ver-se-á a face obscura de Moriana (As cidades e os olhos. 5)

Em geral, a orientação dos diferentes tradutores brasileiros incluídos nesta análise é bastante uniforme, o que parece vir confirmar, pelo menos dentro de um corpus reduzido, homogêneo mas ao mesmo tempo diversificado, a preferência por uma expressão normativizada em PB na tradução deste tipo de registo linguístico e de tipologia textual. A tradução parece pautada pela necessidade de veicular um registo evidentemente literário, e que poderá até resultar mais elevado na perceção do público de leitores brasileiros do que o próprio prototexto. Em especial, um dos elementos que contribuem para tal é a distribuição de verbos no pretérito mais-que-perfeito simples e mais-que-perfeito composto. O primeiro marca uma presença significativa quer nas traduções portuguesas quer na brasileiras, chegando a registar um uso muito mais frequente por parte do tradutor brasileiro de $A$ distância da Lua comparativamente com o tradutor português do mesmo conto, como se pode ver na Tabela 3 mais abaixo.

Além disso, nas ocorrências de pretérito mais-que-perfeito composto, nas traduções brasileiras predomina o verbo auxiliar haver, que não consta das ocorrências das traduções portuguesas.

No caso de $A$ aventura de um soldado, podemos observar a seguinte distribuição de ocorrências nas duas versões portuguesa e brasileira:

\begin{tabular}{|l|c|c|c|}
\hline Versão & $\begin{array}{c}\text { Ocorrências de } \\
\text { pretérito mais- } \\
\text {-que-perfeito } \\
\text { simples }\end{array}$ & $\begin{array}{c}\text { Ocorrências de } \\
\text { pretérito mais- } \\
\text {-que-perfeito sim- } \\
\text { ples com auxiliar } \\
\text { ter }\end{array}$ & $\begin{array}{c}\text { Ocorrências de } \\
\text { pretérito mais- } \\
\text {-que-perfeito sim- } \\
\text { ples com auxiliar } \\
\text { haver }\end{array}$ \\
\hline portuguesa & 11 & 11 & 3 \\
\hline brasileira & 7 & 3 & 24 \\
\hline
\end{tabular}

Tabela 2. Pretérito mais-que-perfeito simples e composto em $A$ aventura de um soldado

As escolhas dos dois tradutores, como se pode ver, levam a um número total de ocorrências diferente, sendo que na tradução portuguesa ao todo há 25 casos de pretérito mais-que-perfeito, ao passo que as ocorrências ascendem a 34 na tradução brasileira. Essa diferença quantitativa prende-se com várias possibilidades tradutivas, como a tradução do trapassato prossimo italiano pelo pretérito perfeito simples, ou uma diferente subordinação, com transposição do tempo italiano para o modo conjuntivo ou outro. $\mathrm{O}$ que, no entanto, é possível averiguar é que o tradutor português privilegia o pretérito mais-que-perfeito simples e o composto com auxiliar ter; pelo contrário, o tradutor brasileiro conta com um número significativo de ocorrências do pretérito mais-que-perfeito simples, porém a opção marcadamente privilegiada é a do pretérito mais-que-perfeito composto com auxiliar haver.

O resultado é aparentemente muito diferente nas traduções de A distância da Lua, como se pode ver pela distribuição de ocorrências indicadas na tabela abaixo: 
Volume 12, n० $17 \mid 2017$

\begin{tabular}{|l|c|c|c|}
\hline Versão & $\begin{array}{c}\text { Ocorrências de } \\
\text { pretérito mais-que- } \\
\text {-perfeito simples }\end{array}$ & $\begin{array}{c}\text { Ocorrências de } \\
\text { pretérito mais-que- } \\
\text {-perfeito simples com } \\
\text { auxiliar ter }\end{array}$ & $\begin{array}{c}\text { Ocorrências de } \\
\text { pretérito mais- } \\
\text {-que-perfeito } \\
\text { simples com } \\
\text { auxiliar haver }\end{array}$ \\
\hline portuguesa & 11 & 12 & 3 \\
\hline brasileira & 18 & 7 & 11 \\
\hline
\end{tabular}

Tabela 3. Pretérito mais-que-perfeito simples e composto em A distância da Lua

Porém, em relação ao nível de formalidade, poder-se-ia concluir de forma não dessemelhante que o metatexto brasileiro soma um número esmagadoramente maior de ocorrências associadas a um registo mais elevado, quer por categoria (cada tipo de pretérito individualmente) quer juntando o pretérito mais-que-perfeito simples com o composto com auxiliar haver.

Dado o caráter mais fragmentário da parte do corpus procedente de As cidades invisíveis, a análise quantitativa deste elemento nesse conjunto de microtextos poderá ser menos significativa, no entanto, podemos comparar o andamento nas duas traduções, que confirma a tendência, por parte do tradutor brasileiro, a preferir um pretérito mais-que-perfeito mais formal:

\begin{tabular}{|l|c|c|c|}
\hline Versão & $\begin{array}{c}\text { Ocorrências de } \\
\text { pretérito mais-que- } \\
\text {-perfeito simples }\end{array}$ & $\begin{array}{c}\text { Ocorrências de } \\
\text { pretérito mais-que- } \\
\text {-perfeito simples com } \\
\text { auxiliar ter }\end{array}$ & $\begin{array}{c}\text { Ocorrências de } \\
\text { pretérito mais- } \\
\text {-que-perfeito } \\
\text { simples com } \\
\text { auxiliar } \text { haver }\end{array}$ \\
\hline portuguesa & 9 & 5 & 3 \\
\hline brasileira & 15 & 1 & 5 \\
\hline
\end{tabular}

Tabela 4. Pretérito mais-que-perfeito simples e composto nas "cidades" de As cidades invisíveis

Outro elemento gramatical que se relaciona, de várias formas, com o verbo é o pronome pessoal. Em relação ao pronome pessoal que expressa complemento de objeto direto ou indireto, em geral as traduções brasileiras analisadas recorrem quase exclusivamente aos clíticos.

Por fim, a tendência maior do PB à explicitação do pronome sujeito em geral não se manifesta no corpus selecionado, onde, aliás, por vezes o metatexto brasileiro omite um pronome sujeito presente no metatexto italiano e/ou no prototexto português. Por exemplo, em A distância da Lua (negrito e sublinhado nossos):

(IT) Ora voi mi chiederete cosa diavolo andavamo a fare sulla Luna, e io ve lo spiego.

(PE) Agora devem estar cheios de vontade de me perguntar que raio íamos nós fazer à Lua, e eu já explica.

(PB) Agora certamente vão me perguntar que Diabo andávamos fazendo na Lua, e eu thes explico. 
A combinação dos elementos descritos ao compararmos as traduções portuguesa a brasileira parece indicar, portanto, uma elevação de registo, evidenciando que os metatextos brasileiros episodicamente apresentam mais elementos associados a um registo elevado, embora a produção textual espontânea em PE seja habitualmente percecionada como mais formal do que a brasileira. É o que se pode vislumbrar no seguinte excerto de A distância da Lua, por combinação de tempos verbais, advérbios e verbos selecionados pelos dois tradutores (negrito e sublinhado nossos):

(IT) Nessuno di noi poteva sospettarlo. Il sordo, forse solo il sordo: nella maniera larvale in cui sapeva lui le cose, aveva presentito che quella notte gli toccava di dar l'addio alla Luna. Per questo si nascose nei suoi luoghi segreti e non ricomparve che per tornare a bordo. E la moglie del capitano ebbe un bell'inseguirlo: la vedemmo attraversare la distesa squamosa più volte, in lungo e in largo, e a un tratto si fermò guardando noi rimasti in barca, quasi sul punto di chiederci se l'avevamo visto.

(PE) Nenhum de nós podia suspeitá-lo. O surdo, talvez só o surdo: na maneira larvar com que sabia as coisas, pressentindo que naquela noite deveria dizer adeus à Lua. Por isso se escondeu nos seus lugares secretos e só reapareceu para regressar a bordo. E a mulher do capitão fartou-se de procurá-lo: vimo-la atravessar a extensão escamosa várias vezes, em comprimento e na largura, e de repente parou a olhar para nós que ficámos no barco, quase como se nos perguntasse se o tínhamos visto.

(PB) Nenhum de nós poderia suspeitar. O surdo, talvez apenas o surdo: da maneira larval com que sabia das coisas, havia pressentido que lhe tocava aquela noite dar adeus à Lua. Por isso, escondeu-se em seus lugares secretos e só reapareceu para voltar a bordo. E a mulher do capitão perdeu tempo em segui-lo: vimo-la atravessar várias vezes a extensão escamosa, para cima e para baixo, e houve um momento em que se deteve a olhar para nós que ficáramos na barca, quase a ponto de nos perguntar se o tínhamos visto.

Se, realmente, é possível atribuir a registos diversos os elementos salientados no exemplo, podemos afirmar que as diferenças em negrito, que testemunham um registo mais cuidado no metatexto brasileiro, com efeito são muito mais numerosas das diferenças sublinhadas, em que acontece o inverso.

Por vezes, trechos extensos dos metatextos brasileiros apresentam uma surpreendente convergência com o PE, sobretudo em As cidades invisíveis traduzidas por Diogo Mainardi. Limitar-nos-emos a dois exemplos ilustrativos:

Ao se transporem seis rios e três cadeias de montanhas, surge Zora, cidade que quem viu uma vez nunca mais consegue esquecer. Mas não porque deixe, como outras cidades memoráveis, uma imagem extraordinária nas recordações. Zora tem a propriedade de permanecer na memória ponto por ponto, na sucessão das ruas e das casas ao longo das ruas e das portas e janelas das casas, apesar de não demonstrar particular beleza ou raridade. O seu segredo é o modo pelo qual o olhar percorre as figuras que se sucedem como uma partitura musical da qual não se pode modificar ou deslocar nenhuma nota. (As cidades e a memória. 4) 
Da cidade de Zirma, os viajantes retornam com memorias bastante diferentes: um negro cego que grita na multidão, um louco debruçado na cornija de um arranha-céu, uma moça que passeia com um puma na coleira. Na realidade, muitos dos cegos que batem as bengalas nas calçadas de Zirma são negros, em cada arranha-céu há alguém que enlouquece, todos os loucos passam horas nas cornijas, não há puma que não seja criado pelo capricho de uma moça. A cidade é redundante: repete-se para fixar alguma imagem na mente. (As cidades e os símbolos. 2)

Nestes casos, o metatexto não deixa transparecer, de fato, qualquer elemento que permita definir a variedade linguística a que pertence.

\section{Considerações finais}

A análise conduzida a partir de um corpus delimitado e homogêneo de traduções literárias para português a partir de uma língua considerada afim, através da comparação dos metatextos produzidos em PE e PB, revelou no caso brasileiro um sistema implícito de normas conservadoras, que determinam a produção de traduções em que os fenômenos de variação linguística estão pouco presentes.

A observação das práticas correntes em outras formas de tradução também reconduzíveis ao plano artístico e ou assimiláveis ao literário, nomeadamente a localização publicitária e a dobragem de filmes de animação, aponta, pelo contrário, para uma divergência marcada entre resultados em PE e em PB. Trata-se, de fato, de outros dois domínios em que cabe ao tradutor uma notável liberdade expressiva, embora tanto o processo de reelaboração do texto publicitário como o de dobragem impliquem um trabalho de equipe em que os profissionais envolvidos são vários e com competências que transcendem e integram o âmbito da tradução em si. Esses dois tipos de prática tradutória caracterizam-se em geral pela informalidade típica da oralidade, por um registo corrente a até mesmo coloquial, que mais facilmente reflete os fenômenos de variação do Português brasileiro, e isso pode explicar a grande distância que separa as línguas representadas na tradução de textos ficcionais, por um lado, e na localização de conteúdos publicitários e na dobragem por outro ${ }^{11}$.

Após décadas desde a sua formulação e muito trabalho de investigação na área da linguística para descrever o rumo atual do PB, constata-se que, com alguma surpresa, no domínio da literatura traduzida parece ainda predominar o "princípio da unidade na diversidade e da diversidade na unidade", retomado de Serafim da Silva Neto que o aplica à situação linguística do Brasil e que a gramática de Celso Cunha e Lindley Cintra estende à situação do português em geral no circunstanciado parágrafo intitulado "Unidade e diversidade da língua portuguesa" no início do capítulo dedicado ao domínio atual da língua portuguesa. Esse binómio tem sido amplamente citado para evidenciar planos de proximidade ou afastamento entre variedades do português, sendo que a produção literária é considerada uma área em que as diferenças internas pouco se notam ${ }^{12}$.

11 Para sustentar criticamente estas afirmações, remete-se para dois recentes trabalhos de mestrado que abordaram precisamente estes temas, nomeadamente os de Lucente (2017) e Zanetti (2017).

12 Cfr. por exemplo um texto disponível no site institucional do Instituto Camões (http://cvc.instituto-camoes. pt/hlp/brevesum/, última consulta 18/04/2017), em particular a passagem "É possível ter percepções diferentes quanto à unidade ou diversidade internas do português, conforme a perpectiva do observador. // Quem se concentrar na língua dos escritores e da escola, colherá uma sensação de unidade. // Quem comparar a língua falada de duas regiões (dialectos) ou grupos sociais (sociolectos) não escapará a uma sensação de diversidade, até mesmo de divisão" (negrito nosso). 
Para poder confirmar ou matizar estas considerações, seria porém necessário alargar o corpus, tanto em termos quantitativos como em termos qualitativos, ou seja, quer aumentando o número de traduções literárias examinadas incluindo tipologias discursivas variadas, quer as línguas-fonte. Em particular, é possível que, ao traduzir de outras línguas menos próximas do português os resultados estejam menos presos à estrutura linguística do prototexto e possam revelar uma maior liberdade expressiva e uma maior abertura à variação.

\section{Apêndice}

"Textualidade e tradução: macrotipos, tipos intermédios e formas textuais concretas" (Scarpa 2001: 22, tradução nossa)

\begin{tabular}{|c|c|c|}
\hline Macrotipos & $\begin{array}{l}\text { Tipos intermédios } \\
\text { e suas funções }\end{array}$ & Formas textuais concretas \\
\hline $\begin{array}{l}\text { Textos muito } \\
\text { vinculadores }\end{array}$ & $\begin{array}{l}\text { Textos científicos } \\
\text { Função meramente cognitiva, baseada } \\
\text { em asserções submetidas a critério de } \\
\text { verdadeiro/falso. }\end{array}$ & $\begin{array}{l}\text { Descrições e definições científicas for- } \\
\text { malizadas (sobretudo de matérias que } \\
\text { possibilitam um tratamento quantitati- } \\
\text { vo dos dados). }\end{array}$ \\
\hline & $\begin{array}{l}\text { Textos normativos } \\
\text { Função prescritiva, baseada numa } \\
\text { manifestação de vontade coercitiva, } \\
\text { regulamentada por um sistema completo } \\
\text { de princípios explícito. } \\
\text { Textos técnicos/operativos } \\
\text { Função instrumental-reguladora, basea- } \\
\text { da na adesão espontânea do destinatário } \\
\text { às instruções fornecidas pelo emissor. }\end{array}$ & $\begin{array}{l}\text { Leis, decretos, regulamentos e outros } \\
\text { textos afins (autos administrativos, } \\
\text { judiciários, notariais, contratos, etc.). } \\
\text { Instruções de utilização (de aparelhos, } \\
\text { instrumentos, substâncias etc.) ou para } \\
\text { efetuar operações (movimentos, jogos, } \\
\text { etc.). }\end{array}$ \\
\hline $\begin{array}{l}\text { Textos media- } \\
\text { mente vincula- } \\
\text { dores }\end{array}$ & $\begin{array}{l}\text { Textos expositivos } \\
\text { Função explicativa/argumentativa, ba- } \\
\text { seada na intenção de explicar a alguém } \\
\text { que não sabe ou propor e debater teses. } \\
\text { Textos informativos } \\
\text { Função informativa, baseada na } \\
\text { intenção de "divulgar" informações, } \\
\text { geralmente aproximativas. }\end{array}$ & $\begin{array}{l}\text { Tratados, manuais, enciclopédias, } \\
\text { ensaios críticos, relatórios, cartas de } \\
\text { negócios, conferências e lições escritas } \\
\text { etc. } \\
\text { Obras de divulgação e de informação } \\
\text { corrente, textos jornalísticos, corres- } \\
\text { pondência familiar e entre amigos. }\end{array}$ \\
\hline $\begin{array}{l}\text { Textos pouco } \\
\text { vinculadores }\end{array}$ & $\begin{array}{l}\text { Textos artísticos/literários } \\
\text { Função expressiva, baseada na intenção } \\
\text { (ou na necessidade) do emissor de } \\
\text { expressar um "modo de sentir" e de } \\
\text { compará-lo com o de outro ser humano } \\
\text { qualquer. }\end{array}$ & $\begin{array}{l}\text { Obras com finalidade artística ou } \\
\text { que adquirem formas artísticas com } \\
\text { outros fins (literatura em prosa e em } \\
\text { poesia; ditados e provérbios; escrituras } \\
\text { sagradas; textos litúrgicos e de oração; } \\
\text { textos publicitários especiais). }\end{array}$ \\
\hline
\end{tabular}


BRITO, Ana Maria; LOHSE Birger; OLIVEIRA NETO Godofredo de; AZEREDO José Carlos. Gramática comparativa Houaiss: quatro línguas românicas: português, espanhol, italiano, francês. São Paulo: Publifolha, 2010.

CALVINO, Italo. A aventura de um soldado. In: Os amores dificeis. Lisboa: Teorema, 2011. Tradução de José Colaço Barreiros.

. A aventura de um soldado. In: Os amores dificeis. São Paulo: Companhia das

Letras, 1992. Tradução de Raquel Ramalhete.

Barreiros.

. As cidades invisíveis. Lisboa: Teorema, 2008 [1993]. Tradução de José Colaço

. A distância da lua. In: Todas as cosmicómicas. Lisboa: Teorema, 2009. Tradução

de José Colaço Barreiros.

. A distância da lua. In: Todas as cosmicômicas. São Paulo: Companhia das Letras, 2007. Tradução de Ivo Barroso.

. As cidades invisíveis. São Paulo: Companhia das Letras, 2009. Tradução de

Diogo Mainardi [1990].

. L'avventura di un soldato. In: Gli amori difficili. Milano: Mondadori, 2015 [1970].

. La distanza della Luna. In: Le cosmicomiche. Milano: Mondadori, 2015 [1965].

. Le città invisibili. Milano: Mondadori, 1993 [1972].

CUNHA, Celso; CINTRA, Luís F. Lindley. Nova gramática do português contemporâneo. Lisboa: Sá da Costa, 2002 [1984].

LUCENTE, Giovanna. Nos dois lados do Atlântico: uma análise contrastiva entre PE e PB na tradução audiovisual de Madagascar. [Dissertação de mestrado] Veneza: Università Ca’ Foscari Venezia, 2017.

MATTOS E SILVA, Rosa Virgínia. O português do Brasil. In: Gramática do Português. Eduardo Buzaglo Paiva Raposo, Maria Fernanda Bacelar do Nascimento, Maria Antónia Coelho da Mota, Luísa Segura, Amália Mendes (Orgs.). Lisboa: Fundação Gulbenkian, 2014, v. 1, p. 145-154.

SCARPA, Federica. La traduzione specializzata: lingue speciali e mediazione linguistica. Milano: Hoepli, 2001.

TOURY, Gideon. Descriptive Translation Studies and Beyond. Amsterdam: Benjamins, 1995.

ZANETTI, Angela. Ensino do português através da publicidade numa perspetiva intercultural. [Dissertação de mestrado] Veneza: Università Ca’ Foscari Venezia, 2017.

Recebido em: 30/04/2017. Aceito em: 04/05/2017 